\section{The Character of the}

\section{Entrepreneurial University}

\section{Burton R. Clark}

Burton R. Clark is the Allan M. Cartter Professor Emeritus of Higher Education, in the Graduate School of Education and Information Studies, University of California at Los Angeles, Los Angeles, CA 90095, USA. Email: clark@gseis.ucla.edu.

Tow are entrepreneurial universities initially formed and How do they sustain themselves? In Creating Entrepreneurial Universities (Pergamon-Elsevier, I998), I traced developments in a few European universities from I980 to I995 to determine how they had gone about significantly changing the way they operated-how they moved to a much more proactive style. I argued that five pathways of transformation could be induced from these cases: diversified funding base; strengthened steering core; expanded developmental periphery; stimulated academic heartland; and integrated entrepreneurial culture. More recently, my latest book, Sustaining Change in Universities: Continuities in Case Studies and Concepts (Open University Press, 2004), substantially expands on that earlier analysis and provides a further look at the evolving character of the entrepreneurial university.

In the new book I searched for exemplars of entrepreneurial action-and stronger conceptualization. I turned to I4 internationally distributed case studies to clarify anew the earlier stated pathways of transformation and, further, to suggest dynamics that produce a new steady state committed to ongoing change. Five narratives pursue sustaining developments during the late I990s in the European universities previously studied: the University of Warwick in England, the University of Strathclyde in Scotland, the University of Twente in the Netherlands, the University of Joensuu in Finland, and Chalmers University of Technology in Sweden. Three new accounts, drawn from the work of other scholars, portray transformed universities in Africa (University of Makerere in Uganda), Latin America (Catholic University of Chile), and Australia (Monash University). Additional brief narratives report on six diverse research universities in the United States (two private, four public), which exemplify aggressive institution building under the spur of intense competition-Stanford and MIT, Michigan and UCLA, North Carolina State University and Georgia Institute of Technology.

The newly highlighted dynamics of change stress, first, mutually supportive interaction among transforming elements; second, a newly established forward-looking "perpetual momentum"; and, third, behind the scenes, an institutionalized volition, a collective will, stimulates and guides a self-sustaining and self-selecting forcefulness in responding to societal demands. In one case after another, we find an assertive "bureaucracy of change": such professional staff as development officers, grants and contracts officers, and continuing education officers-nonacademic personnel who are much more forward-oriented than the traditional "administrative" staff who served on behalf of the funding public authority and higher regulatory boards and councils. We see the overall sustaining capacity become a virtual steady state of change, a character not dependent on a commanding CEO or a brilliant management team. Change becomes a habit, an institutionalized state of being.

Since each university is unique in combining common elements with particular features, the case studies produce "amplifying variations" of the overall themes. Chalmers, in Sweden, illuminates particularly well how to generate centers of initiative in a small to medium-size university; the Catholic University of Chile dramatizes how to modernize an old-fashioned faculty in a decade and a half; the University of Michigan reveals how a massive public university, busily multiplying resources, can match up against the sharp competition of the richest private universities in the world. The exhibited variations are as much a source of transferable insight as the old and new concepts that bring formal order to wide-ranging empirical examination of very complex entities. Case study narratives additionally weave uniquenesses around common elements and their amplifying variations. There is, finally, only one MIT, one Twente, one Monash.

Everywhere, increased accountability has subjected academics to bureaucratic controls and has weakened academic autonomy.

Without doubt, active complex universities, operating in different complex environments, develop complex differentiated answers. In contradistinction to system-level analysis, institution-level inquiry stays close to those realities. System analysis misses key aspects of university development, particularly the organic nature of university change. It readily loses its way in the swirling fog of national policy statements and the iron cages of categorical state steering. Institutional studies are better grounded.

In short, institutional case studies allow us to identify instructive exemplars of successful university adaptability under a wide range of and cultural conditions in various societies. The needed exemplars provide on-the-ground demonstration of how, in the study of universities, we can combine research for use with research for understanding.

From such cumulative analysis, we gradually grasp the entrepreneurial university as a place possessing a capacity for change. We learn also that within universities there is a collective phenomenon, an accumulation of entrepreneurial groups stretching from disciplinary departments and interdisciplinary and transdisciplinary research centers at the base, to faculties and schools at intermediary levels, to the entire university. We find faculty and managers intertwined at all levels, encased in 
a common understanding that academic values are the bedrock upon which managerial values are brought into play.

Perhaps most enabling of all, we find the entrepreneurial university to be a place that diversifies income to the point where its financial portfolio is not heavily dependent upon the whims of politicians and bureaucrats who occupy the seats of state policy, nor upon business firms and their "commercial" influence, nor even upon student tuition as main support. Funds flow not only from such well-identified sources but also, crucially, from a host of public agencies (other than the coresupport ministry or department) and alumni and other private donors who provide moral and political support as well as direct year-to-year funding and accumulation of endowment. Effective stewardship comes to depend not on the state or on "the market," but on university self-guidance and self-determination. The entrepreneurial university does indeed provide a new basis for achievement.

My qualitative case studies of exemplars of change offer a strong lesson for future research. Concepts induced from exemplary practices are strengthened by the reassurance of solid facts-documented actions taken in defined contexts. More good case studies that lay bare those facts will be needed to further illuminate the character of entrepreneurial universities emerging and evolving at a rapid rate, internationally, in the early years of the 2ist century.

\section{New Typologies for Crossborder Higher Education}

\section{JANE KNIGHT}

Jane Knight is adjunct professor at the Ontario Institute for Studies in Education, University of Toronto. She is currently a visiting scholar at ITAM in Mexico and adviser to GX4 UEALC Project of CENEVAL. E-mail: janeknight@sympatico.ca.

G iven the increase in demand for higher education, there are new providers, new delivery methods, and types of programs. These new providers include media companies such as Pearson (U.K.), Thomson (Canada); multinational companies such as Apollo (USA), Raffles (Singapore), and Aptech (India); corporate universities such as those run by Motorola and Toyota, and networks of universities, professional associations, and organizations. Generally, these new commercial providers are mainly occupied with teaching/training or offering services and do not focus on research per se. They can complement, cooperate, compete, or simply coexist with the traditional public and private higher education institutions with the traditional mandate of teaching, research, and outreach.

It is not just for-profit companies that are becoming increasingly interested in commercial crossborder initiatives.
Conventional higher education institutions, both private and public, are also seeking opportunities for commercial delivery of education programs in other countries. The majority of these are bona fide institutions that comply with domestic and foreign regulations (where they exist), but also on the increase are rogue or low-quality providers who are not recognized by bona fide accreditation/licensing bodies. Another worrisome development is the mushrooming of "degree mills" operating around the world. Many of these ventures are nothing more than web-based companies that are selling certificates based on "life experiences" and are not delivering education programs at all.

The expansion in number and type of entities that are providing education courses and programs across borders is causing some confusion. This also applies to the increasing diversity in delivery modes. The general state of flux may indicate progress and innovation, but it also begs for some kind of classification system or typology to make sense of the new context of crossborder education.

\section{The word "provider" is used as a generic term to include all types of higher education institutions as well as companies and networks involved in crossborder education.}

\section{Classifying Crossborder Providers}

A typology for six different types of crossborder providers is presented. A key factor is that the type of provider is purposely separated from the mode of mobility. To date, much of the discussion about program and provider mobility has linked the type of provider with a certain mode of delivery. This approach is one reason for the state of confusion. A generic classification system for crossborder providers has thus been proposed and separate classification systems are used for the different modes of program and provider mobility.

This typology is a work in progress. The word "provider" is used as a generic term to include all types of higher education institutions as well as companies and networks involved in crossborder education. Four key factors are used to describe each category of provider and to distinguish one group from another: whether the provider is public, private, or religious; whether it is nonprofit or for-profit; whether it is recognized by a bona fide national licensing or accrediting body; and whether it is part of the national "home" higher education system.

The first category includes "recognized higher education institutions" and can be public, private, or religious institutions - either nonprofit or profit-oriented. The institutions are usually part of the home national education system and are recognized by a domestic bona fide licensing or accrediting body, and are often referred to as the traditional type of higher education institution.

"Nonrecognized higher education insitutions" comprise the second group and are usually private in nature and for-profit in 